\title{
LA CONMOCIÓN INTERIOR: EL JUICIO DE CONSTITUCIONALIDAD A LA LUZ DE LA CONSTITUCióN POLÍTICA DE COLOMBIA DE 1991*
}

\author{
Mary Luz Tobón Tobón
}

Fecha de recepción: 30 de agosto de 2015

Fecha de evaluación: 8 de marzo de 2016

Fecha de aprobación: 5 de abril de 2016

Artículo de reflexión

DOI: http://dx.doi.org/10.18359/prole.1975

Forma de citación: Tobón, M. (2016). La conmoción interior: el juicio de constitucionalidad a la luz de la Constitución Política de Colombia de 1991. Revista Prolegómenos Derechos y Valores, 19, 38, 145-160. DOI: http://dx.doi. org/10.18359/prole.1975

\section{Resumen}

Con el presente artículo se busca realizar un análisis sobre la declaratoria del Estado de excepción de conmoción interior a la luz de la Constitución Política de Colombia de 1991, para demostrar las tensiones que se dan en el poder ejecutivo y el poder judicial en los planos político, jurídico, constitucional y legal durante la declaratoria del Estado de conmoción interior desde una perspectiva evolutiva, descriptiva y analítica. Para tal fin, este documento se desarrolla en tres secciones: se aborda el Estado de sitio en la Constitución de 1886; el Estado de conmoción interior, determinando su naturaleza y límites de conformidad con la Constitución Política de 1991, y finalmente se concluye el artículo con el juicio de inconstitucionalidad que debe realizar la Corte Constitucional para determinar la constitucionalidad o no de un decreto legislativo.

\section{Palabras clave:}

Estado de excepción, conmoción interior, control constitucional, juicio de constitucionalidad.

\section{THE INTERNAL UPHEAVAL: THE JUDGMENT OF CONSTITUTIONALITY IN LIGHT OF THE 1991 POLITICAL CONSTITUTION OF COLOMBIA}

\begin{abstract}
Summary
This article seeks to carry out an analysis of the declaration of the State of exception of internal upheaval in the light of the Colombia's Political Constitution of 1991, to demonstrate the

El presente artículo es producto de la investigación titulada "Los Estados de excepción en Colombia: un análisis a partir de los derechos humanos y la Constitución Política de 1991", adscrita al Grupo de Investigación Ratio Juris de la Universidad Autónoma Latinoamericana (Medellín, Colombia).

** Abogada, especialista en Derecho Administrativo y doctora en Estudios Superiores de Derecho Constitucional de la Universidad Complutense de Madrid (Madrid, España). Docente de la Universidad Autónoma Latinoamericana y de la Universidad de Antioquia (Medellín, Colombia). Correo electrónico: mary.tobon@unaula.edu.co
\end{abstract}


tensions that occur in the executive branch and the judicial branch at the political, juridical, constitutional and legal levels during the declaration of the state of internal upheaval from an evolutionary, descriptive and analytical perspective. To that end, this document is developed in three sections: it deals with the state of emergency in the Constitution of 1886; the state of internal upheaval, determining its nature and limits in accordance with the Political Constitution of 1991, and finally the article concludes with the judgement of unconstitutionality which has to be made by the Constitutional Court to determine the constitutionality or otherwise of a legislative decree.

\title{
Keywords:
}

State of exception, internal upheaval, constitutional control, judgement of unconstitutionality.

\section{A COMOÇÃO INTERIOR: A AÇÃO DE CONSTITUCIONALIDADE À LUZ DA CONSTITUIÇÃO PÓLÍTICA DA COLÔMBIA DE 1991}

\begin{abstract}
Resumo
O presente artigo tem o objetivo de realizar uma análise sobre a ação declaratória do Estado de exceção de comoção interior à luz da Constituição Política da Colômbia de 1991, para demostrar as tensões que acontecem no poder executivo e no poder judiciário nos planos político, jurídico, constitucional e legal durante a ação declaratória do Estado de comoção interior desde uma perspectiva evolutiva, descritiva e analítica. Para tal fim, este documento é desenvolvido em três seções: são abordados o Estado de sítio na Constituição de 1886; o estado de comoção interna, determinando a sua natureza e limites em conformidade com a Constituição Política de 1991, e finalmente o artigo é concluído com o julgamento de inconstitucionalidade que deve realizar a Corte Constitucional para determinar a constitucionalidade ou não de um decreto legislativo.
\end{abstract}

\section{Palavras-chave:}

Estado de exceção, comoção interna, controle constitucional, ação de constitucionalidade.

\section{Introducción}

A lo largo de la historia constitucional de Colombia, se han presentado transformaciones políticas, jurídicas, económicas y sociales; siendo necesario en los diferentes periodos presidenciales acudir a la figura del Estado de excepción de conmoción interior, para restablecer el orden y el equilibrio turbado por circunstancias que podrían llegar a poner en riesgo la seguridad de la nación o de cierto territorio.

Los Estados de excepción por naturaleza delimitan la frontera entre normalidad y anormalidad en el desarrollo del ordenamiento constitucional, puesto que solo se ponen en marcha ante una situación de anormalidad y traen consigo una serie de limitaciones y facultades que permiten el mantenimiento o el retorno a la anormalidad. Sin embargo, progresivamente debido a las tensiones sociales y políticas del país, el ejecutivo de turno, de una u otra forma, ha distorsionado la figura, mediante la declaración del Estado de excepción o a su aplicación de facto, casi de manera permanente, convirtiendo lo "anormal" en "normal".

Por lo tanto, y dado que estas declaraciones se convierten en una amenaza latente para la pobla- 
ción colombiana debido a la vulneración de sus derechos fundamentales, es indispensable ponerle cortapisas y control al abuso del poder. El control se convierte entonces, en un elemento clave en la constitución del Estado social y democrático de derecho, pues desde esta denominación se materializa el sistema de restricciones efectivas al poder. Por ello, el constituyente de 1991, al establecer un nuevo régimen de Estados de excepción, partió de la idea de que ni siquiera en situaciones de anormalidad institucional le asisten facultades ilimitadas al ejecutivo. En esa medida, la configuración de los límites debe acompañarse de un sistema eficaz de controles destinados a garantizarlos (sentencia C-802/2002).

En Colombia se limita el poder omnipotente que se le otorga al ejecutivo durante los Estados de excepción, distribuyendo el control entre las otras dos ramas del poder, vale decir, la legislativa y la judicial, con el fin de equilibrar el desbalance que rompe el principio democrático con la declaratoria del Estado de anormalidad. Pueden señalarse dos tipos de controles: uno de carácter jurídico y otro de índole política que recaen tanto sobre la declaratoria del Estado de excepción, como sobre los decretos legislativos de desarrollo. Dichos controles no resultan excluyentes, porque tienen finalidades distintas, $y$ lo más importante es que ambos salvaguardan las garantías de los ciudadanos durante el Estado de conmoción interior.

Si bien la Constitución de 1991 reglamentó el control de los tres tipos de Estado de excepción: Estado de guerra exterior (art. $212 \mathrm{CP}$ ), Estado de conmoción interior (art. $213 \mathrm{CP}$ ) y Estado de emergencia económica, social y ecológica (art. $215 \mathrm{CP}$ ), en el presente artículo se abordarán algunos aspectos generales sobre el control de los Estados de excepción, pero solo se hará énfasis en el control del Estado de conmoción interior, y de manera específica analizaremos el control jurídico resaltando los presupuestos que deben tenerse en cuenta por la Corte para poder llevar a cabo el juicio de constitucionalidad sobre los decretos legislativos, para determinar si las distintas declaratorias se ajustan o no la Consti- tución Política. Por lo tanto, en este artículo se dará respuesta a la pregunta: ¿cómo se realiza el control constitucional de los decretos legislativos expedidos por el presidente de la República durante el Estado de conmoción interior? Para dar respuesta a esta inquietud, la estructura de este artículo se desarrolla en tres momentos de análisis: en el primero se abordarán algunos rasgos generales del Estado de sitio en el régimen de la Constitución de 1886; en el segundo se analizará el Estado de conmoción interior, determinando su naturaleza y límites de conformidad con los artículos 213 y 214 de la Constitución Política de 1991, y en el tercer momento se reflexionará sobre el juicio de inconstitucionalidad que debe realizar la Corte Constitucional para determinar la constitucionalidad o no de un decreto legislativo.

Sin duda alguna, el objeto de estudio de esta investigación requiere un tratamiento más amplio y profundo en el campo de las ciencias jurídicas, pues aunque el tema reviste especial interés para la población colombiana, no ha tenido el mismo eco en la doctrina nacional. En efecto, al realizar un rastreo bibliográfico o de trabajos monográficos que guarden relación con la presente investigación, se encontró que algunos autores recientes como Pedro Pablo Camargo, con su texto Los Estados de excepción (2008) y Clara Elena Reales Gutiérrez, en su ensayo "El control de los decretos declaratorios de los Estados de excepción" (2007) tratan el tema desde el marco general de los Estados de excepción, sin que se especifique el asunto vinculado con el juicio de constitucionalidad hecho por la Corte Constitucional a los decretos legislativos.

Por lo anterior, y debido a la escasez de trabajos investigativos que aborden en profundidad la figura del Estado de conmoción interior en el país, la utilidad de este artículo está totalmente justificada ${ }^{1}$.

Para ampliar la información sobre los Estados de excepción en Colombia, se puede consultar nuestra tesis doctoral intitulada: "La imposibilidad de suspensión de los derechos humanos y las libertades fundamentales durante los Estados de excepción en Colombia: análisis desde el derecho constitucional e internacional de los 


\section{A. El Estado de sitio en la Constitución de 1886}

Con base en la idea del derecho como gramática de guerra y en la visión de la independencia como creación del Estado, antes de la nación y sin la nación, de forma autoritaria y legalista, Colombia no pudo escapar a la influencia que ejerció la figura del Estado de excepción en Latinoamérica y en el resto del mundo, por ello con la vigencia de la Constitución de 1886 el Estado de excepción fue usado irrazonablemente para controlar la violencia política y el fenómeno del narcotráfico sin que tuviera éxito alguno, siendo la población civil la más perjudicada, al ver menguados sus derechos fundamentales por las prácticas abusivas del poder.

En efecto, la Constitución que marcó la ruptura de la facultad discrecional o de las pronunciadas limitaciones impuestas por el legislativo, fue la Constitución centenaria de 1886; donde el Estado de sitio se previó en su artículo 121, y si bien dicha figura era aplicable de forma excepcional, se convirtió en herramienta permanente del ejecutivo. Lo "anormal" se hizo "normal" y la línea que separaba lo convencional de lo excepcional, se hundió en un sinnúmero de decretos legislativos, ante la ineficacia de las instituciones del Estado para hacer frente a la criminalidad que había en aquella época.

Para referirnos a las facultades extraordinarias que tenía el ejecutivo desprendidas del Estado de sitio, es pertinente aludir al artículo 121 de la Carta de 1886, resaltando que si bien la referida disposición nunca tuvo un cambio sustancial, sí fueron múltiples las reformas a la misma a lo largo de más de un siglo de vigencia. La primera de estas, acaeció con el acto legislativo de 1910, que en un primer intento por restringir los excesos del ejecutivo, cambió la expresión del inciso segundo del transcrito artículo: "las

derechos humanos", presentada ante la Universidad Complutense de Madrid en el año 2015 para obtener el título de doctor en Estudios Superiores de Derecho Constitucional". facultades que le confieren las leyes" por la de "facultades legales", y es que lo que se pretendía con esta expresión "era otorgar al ejecutivo por parte del Congreso las facultades precisas, con el fin de morigerar la potestad extraordinaria que se desprendía del artículo 121 a favor del presidente" (Gómez, 1985, p. 156).

Para García y Uprimny (2009) al amparo de ese régimen de excepción, el Gobierno no solo expidió normas relativas a todos los aspectos de la vida social -sustituyendo así de facto al Congreso como legislador-, sino que su vigencia posibilitó la violación de numerosos derechos de los ciudadanos. Así, un régimen que debía ser de excepción y de duración transitoria, conforme con lo preceptuado por el artículo 121 de la Carta de 1886, en la práctica se convirtió en un elemento normal y cotidiano de ejercicio del poder político, con lo cual el régimen constitucional se desfiguró.

Según Valencia (1997) para buscar el uso racional de los Estados de excepción, el artículo 121 sufrió algunos cambios, a través de los siguientes actos legislativos: el artículo 33 del acto legislativo 3/1910 modificó este artículo en el sentido de que el presidente no puede derogar las leyes, sino tan solo suspenderlas cuando son incompatibles con la guarda del orden público, y mientras dure la perturbación; igualmente los decretos legislativos se hacen transitorios y no permanentes.

El acto legislativo 1/1960 introdujo el control político por parte del Congreso y un control jurisdiccional por parte de la Corte Suprema de Justicia, previa solicitud del Congreso, avanzando así, teóricamente hacia una limitación del ejecutivo frente a estas facultades.

Por último, el acto legislativo 1/1968 estipuló la limitación de las facultades extraordinarias en el derecho internacional humanitario, consagrando un control jurisdiccional automático de todas las normas dictadas por el presidente, por parte de la Corte Suprema de Justicia y creó el Estado de conmoción del orden económico o social, pues hasta esta reforma, los Estados de excepción se circunscribían a consagrarse por motivos de orden público. 
De este modo, el uso del régimen excepcional por parte del ejecutivo en vigencia de las constituciones comentadas fue excesivo y abusivo, debido a la ausencia de controles para impedir que los presidentes no solo se aprovecharan de competencias legislativas que constitucionalmente no les pertenecían, sino que además legislaban sobre todas las materias, so pretexto de preservar o restablecer el orden público perturbado.

A pesar del cada vez mayor número de decretos y herramientas jurídicas que el ejecutivo expedía para la lucha contra la criminalidad y el terrorismo, la ofensiva de los insurgentes se acrecentó. El Gobierno de Belisario Betancur Cuartas (1982-1986) tampoco escapó del actuar bélico de estos grupos, un caso palpable fue en el año de 1984 cuando el M-19 se tomó la ciudad de Florencia en el mes de marzo. Otro caso que rechazó el pueblo colombiano fue el magnicidio del ministro de Justicia Rodrigo Lara Bonilla, un mes y medio después a manos del implacable Cartel de Medellín, sucesos que llevaron a que el presidente Betancur decretara el Estado de sitio de forma indefinida mediante decreto 1038/1984.

Sin embargo, el Estado seguía quedándose corto para contener la amenaza de seguridad que se cernía sobre la ciudadanía, y las medidas de excepción seguían siendo ineficaces; prueba de ello, fue la creciente presencia de los carteles de la droga, grupos insurgentes y aparición de grupos de autodefensas (Iturralde, 2005), así como la toma al Palacio de Justicia el 6 de noviembre de 1985 por parte del M-19 y los nefastos efectos posteriores a raíz de esta.

Sin duda alguna, durante el periodo comprendido entre abril de 1984 y julio de 1991, Colombia estuvo guiada por el régimen de excepción ${ }^{2}$; la

2 Valga recordar que mediante decreto 1038/1984 se declaró el Estado de sitio para todo el territorio colombiano, y continuó vigente hasta que se expidió la Constitución de 1991. De hecho, la Constitución de 1991 encuentra su antecedente más remoto en un decreto legislativo. Para ampliar el tema véanse los decretos legislativos 926/1990 y 1926/1990, revisados por la Corte Suprema mitad del Gobierno de Betancur, el periodo de Gobierno completo de Virgilio Barco y el primer año de la administración de César Gaviria (Iturralde, 2005). Este panorama de crisis y de anormalidad, aunado a la expedición de medidas de emergencia, que resultaron ineficaces para controlar el orden público y los nuevos actores que aparecían en la realidad colombiana como el narcotráfico, guerrillas y paramilitarismo, dejaron vislumbrar claramente la insuficiencia y la poca capacidad operativa del Estado para poner coto al desmesurado proceder del narcoterrorismo. Sobre el uso desmedido del artículo 121 de la Constitución de 1886³ , Gustavo Gallón expresa:

El Estado de sitio, una falacia antidemocrática: esta breve reseña, aunque circunscrita al caso colombiano, permite hacer unas consideraciones más generales acerca de la naturaleza del Estado de sitio, al menos en lo que se refiere a su aplicación en situaciones de conflicto interno, tal como se ha dado en Colombia. De la experiencia allí vivida se aprecia claramente que el Estado de sitio es una falacia, que su utilización está íntimamente relacionada con la militarización de la sociedad $y$, en fin, que se trata de una institución profundamente antidemocrática (1987, pp. 80-81).

En el mismo sentido, Uprimny opina que

[...] desde el cierre del Congreso -en noviembre de 1949, durante el Gobierno de Mariano Ospina Pérez (1946-1950)- hasta la expedición de la Constitución de 1991, Colombia vivió prácticamente en un régimen de excepción permanente, pues de esos 42 años, 35 transcurrieron bajo Estado de sitio $(2007, \text { p. } 55)^{4}$.

de Justicia mediante sentencias 59 del 24 de mayo de 1990 y 138 del 9 de octubre de 1990.

3 Para una presentación histórica y panorámica de los regímenes de excepción en Colombia, véanse Gallón (1979), García (2001) y Barreto (2006).

4 Para García: "en Colombia, la Constitución pocas veces ha regido en forma plena. Una prueba de ello es el recurso permanente que los gobiernos han hecho a los 


\section{B. El Estado de conmoción interior: su naturaleza, límites y la discrecionalidad del presidente}

\section{Naturaleza}

Su hecho habilitante es la grave perturbación del orden público que atente de manera inminente contra la estabilidad institucional, la seguridad del Estado o la convivencia ciudadana, en todo caso que no pueda ser conjurada mediante el uso de las atribuciones ordinarias de las autoridades de policía, tal como se desprende del artículo 213 de la Constitución Política.

Sobre la competencia se indica que la declaración del Estado de conmoción interior en todo el país o parte de la República, requerirá la firma de todos los ministros. El nuevo artículo 213 consagró la declaratoria por un término inicial de "90 días prorrogables por dos periodos iguales siempre y cuando medie concepto previo y favorable del Senado".

Si bien a dicha declaratoria se le impuso un límite temporal debido al uso desmedido de las atribuciones de emergencia que el ejecutivo tenía antes de la nueva Carta, cuando de forma indefinida y casi permanente aplicaba normas que prolongaban su vigencia incluso más allá de la alteración del orden constitucional. Para Camargo (2008) si el año tiene 365 días, un Estado de conmoción interior puede abarcar tres periodos de noventa días, para un total de 270 días. Y como el Gobierno puede prorrogar los decretos de conmoción interior por noventa días

mecanismos de excepción. Así, en la época de la llamada Regeneración (1886-1910), el país fue gobernado durante 24 años con base en una norma 'transitoria' -la disposición $\mathrm{K}-\mathrm{y}$ en una ley muy represiva -la Ley 61 de 1888 o Ley de los Caballos-, que autorizaban al Ejecutivo a reprimir administrativamente 'los abusos de prensa', 'los delitos contra el orden público', las conspiraciones, etc. Luego, durante el gobierno de Miguel Abadía Méndez (1926-1930), se expidió la Ley Heroica, que dio tratamiento policial a las protestas sociales que surgían por el inicio de la industrialización" (en De Sousa y García, 2001, p. 317). más, entonces la conmoción interior puede tener un total de 360 días, quedando unas vacaciones de cinco días para el pueblo colombiano.

El nuevo articulado impone un elemento central y es que "la grave perturbación del orden público no pueda ser conjurada mediante el uso de atribuciones ordinarias de las autoridades de policía", en este sentido, se limita la discrecionalidad del ejecutivo quien deberá presentar las pruebas pertinentes ante la Corte Constitucional con el fin de que esta declare la satisfacción del presupuesto de suficiencia que impone la Carta. Para esta evaluación, la Corte Constitucional decreta pruebas, incluyendo informes justificativos de los factores de perturbación (Camargo, 2008).

Otros asuntos importantes que señaló el artículo 213 de la Constitución de 1991 son los siguientes: (i) determinó el espacio físico en el que puede declararse, indicando que procedía en todo el territorio nacional o en una parte de él; (ii) fijó el término durante el cual podía estar vigente la declaratoria, limitándolo a noventa días prorrogables por dos periodos iguales y sometiendo la última prórroga al concepto previo y favorable del Senado de la República; (iii) indicó que las facultades conferidas eran las estrictamente necesarias para conjurar las causas de la perturbación del orden público e impedir la extensión de sus efectos y (iv) habilitó al presidente para dictar decretos legislativos, que pueden suspender las leyes incompatibles con el Estado de conmoción interior que dejan de regir tan pronto se declare restablecido el orden público, pero cuya vigencia se puede prorrogar hasta por noventa días más con autorización del Senado.

\section{La discrecionalidad del presidente}

La Constitución en los artículos 213 y 214 le otorga al presidente la facultad de declarar, con la firma de todos los ministros, el Estado de conmoción interior. La declaración conlleva la alteración temporal del principio de división de poderes, dado que se concentra en el ejecutivo la facultad legislativa a través de la expedición 
de decretos legislativos. A su vez, el artículo 213 de la misma ley fundamental establece que: "mediante tal declaración, el Gobierno tendrá las facultades estrictamente necesarias para conjurar las causas de la perturbación e impedir la extensión de sus efectos".

Según el artículo 214-5 de la Constitución Política, el presidente de la República y los ministros serán responsables cuando declaren los Estados de excepción sin presentarse las circunstancias extraordinarias previstas en la Carta Magna. Por lo tanto, la determinación de los supuestos de hecho configuradores de los Estados de excepción, por parte del presidente, no reflejan ningún poder discrecional. Si bien los hechos que integran las causales de los Estados de excepción, se enuncian en la Constitución mediante fórmulas o conceptos jurídicos indeterminados -grave perturbación del orden público, amenaza a la estabilidad institucional, grave daño a la convivencia ciudadana, etc.-, estos son determinables conforme con el presupuesto fáctico.

En efecto, a partir de la Constitución de 1991 la figura del Estado de excepción en Colombia se ha inclinado por un modelo intermedio, que concede al ejecutivo una serie de poderes adicionales con los cuales puede suspender algunos derechos y garantías constitucionales de manera temporal $-\mathrm{y}$ hasta que se restablezca el ordenen los casos determinados taxativamente en la Carta, y en un sistema de controles que limitan el uso de dichas prerrogativas ${ }^{5}$.

En una posición intermedia -la que en parte recogen los instrumentos internacionales de derechos humanos-, se ha intentado regular de forma restrictiva el poder de excepción, a fin de evitar abusos, basándose en algunas ideas esenciales: delimitar con rigor las causales de los Estados de excepción y su temporalidad; definir

\footnotetext{
5 La doctrina básica de la Corte Constitucional sobre la discrecionalidad del presidente durante los Estados de excepción, ha sido expuesta en numerosos fallos, tales como: sentencias C-004/1992, C-300/1994, C-466/1995, C-027/1996, C-802/2002 y C-070/2009.
}

con precisión las facultades de las autoridades y los derechos limitables, indicando además que su restricción debe ajustarse a ciertos principios, como los de proporcionalidad, temporalidad y necesidad y, en consecuencia, fortalecer los mecanismos judiciales y políticos de control a los eventuales abusos (García, 2009). En este sentido, el exmagistrado de la Corte Constitucional Eduardo Cifuentes Muñoz, considera que:

Se le debe reconocer al presidente un margen necesario -la Corte lo califica de "discreto"- de apreciación e interpretación de la realidad subyacente, pese a que no puede ignorar la existencia real de los hechos que dan base a sus calificaciones, ni sustraerse a un escrutinio lógico y racional del nexo de probabilidad que pueda enlazarse a sus manifestaciones y previsiones, así como de la misma congruencia de su argumentación a la luz de las circunstancias cuya existencia se proclama (sentencia C-004/1992).

En todo caso, declarado el Estado de excepción, según el artículo 189-4 de la Constitución Política, el presidente es el responsable de conservar y restablecer el orden público en todo el territorio nacional. El restablecimiento del orden alterado por los hechos perturbadores, no sería posible si no se reconoce en cabeza del mandatario un adecuado margen de discreción. Pero, no se trata de una facultad reglada, en cuanto deben cumplirse ciertos límites y presupuestos constitucionales y legales, para que la declaratoria no sea arbitraria. En consecuencia, la discrecionalidad consiste en la posibilidad de decidir políticamente el momento necesario y oportuno para hacer la declaratoria, teniendo en cuenta que es imposible reglamentar las situaciones "anormales" de manera abstracta.

\section{Límites}

La Constitución Política también condiciona las facultades que con base en el Estado de excepción, puede ejercer el primer mandatario y el ámbito que puede ser objeto de regulación legislativa de excepción. Así, por un lado, cuando 
la Carta en el artículo 213 determina el alcance de las facultades conferidas al presidente, señala que ellas serán "las estrictamente necesarias para conjurar las causas de la perturbación e impedir la extensión de sus efectos". Y luego, cuando desarrolla las disposiciones a que quedan sometidos los Estados de excepción, dispone que los decretos legislativos expedidos con base en ellos "solamente podrán referirse a materias que tengan relación directa y específica con la situación que hubiere determinado la declaratoria del Estado de excepción".

En tal contexto, atendiendo a los principios de necesidad (art. 213 , inc. $2 \mathrm{CP}$ ) y proporcionalidad (art. 214, núm. 2) el presidente no puede asumir cualquier facultad durante el Estado de conmoción interior, pues solo puede ejercer aquellas medidas necesarias para conjurar la grave perturbación del orden público. Además, de conformidad con el principio de especificidad (art. 214, núm. 1) las materias que desarrolle como legislador de excepción deben relacionarse con los hechos que generaron esa grave alteración. Estos principios han sido objeto de un detenido desarrollo por parte del derecho internacional de los derechos humanos.

No obstante, en vigencia de la conmoción interior, el presidente podrá adoptar muchas de las medidas asociadas con el Estado de guerra exterior, como son: someter a permiso previo o restringir la celebración de reuniones y manifestaciones públicas; ordenar la aprehensión preventiva de personas; limitar o racionar el consumo de servicios o de artículos de primera necesidad; imponer contribuciones fiscales o parafiscales que no figuren en el presupuesto de rentas o efectuar erogaciones aún no incluidas en el de gastos; modificar el presupuesto; suspender la vigencia de salvoconductos para el porte de armas; tipificar penalmente algunas conductas; aumentar $y$ reducir penas; $y$ modificar el procedimiento penal.

Las medidas son amplísimas en número, alcance y contenido. Sin embargo, la ley 137/1994 que regula el Estado de excepción en Colombia, es- tableció tres prohibiciones: (i) durante el Estado de conmoción interior "no podrán suspenderse los derechos humanos ni las libertades fundamentales" (art. 214-2); (ii) "los civiles no podrán ser investigados o juzgados por la justicia penal militar" (art. 42); y (iii) "no podrá privarse a los municipios de sus ingresos o recursos ordinarios" (art. 45).

De este modo, para la Corte Constitucional la propia Constitución de 1991 impone una serie de límites a las facultades que se otorgan al primer mandatario durante los Estados de excepción, y son:

1. Principio de necesidad y principio de especificidad, esto es, la necesidad de las actuaciones para afrontar la perturbación (art. 213, inc. 2) y su relación directa y específica con la misma (art. 214, núm. 1).

2. La imposibilidad de suspender derechos humanos y libertades fundamentales y respeto por las normas del derecho internacional humanitario (art. 214, núm. 2) ${ }^{6}$.

3. Principio de proporcionalidad. Entre las medidas que se adopten y la gravedad de los hechos (art. 214, núm. 2).

4. La no interrupción del normal funcionamiento de las ramas del poder público ni de los órganos del Estado (art. 214, núm. 3).

5. La no investigación ni juzgamiento de civiles por la justicia penal militar (art. 213, núm. 5) (Corte Constitucional, sentencia C-802/2002).

\footnotetext{
$6 \quad$ Cuando la Carta se refiere a los "derechos humanos y libertades fundamentales", se remite a los derechos y libertades reconocidos y garantizados en lo que la doctrina constitucional ha definido como "bloque de constitucionalidad", esto es, aquellas normas jurídicas que, aunque no tienen consagración expresa en el derecho interno, tienen plena vigencia en este. Este límite en nuestra opinión, es el más importante, toda vez que busca salvaguardar los derechos humanos durante los Estados de excepción.
} 
Por último, como novedades de la nueva reglamentación del Estado de conmoción interior, se destacan las siguientes: (i) causales más estrictas para la declaratoria y que estas sean verdaderamente extremas y excepcionales; (ii) elimina la vigencia indefinida del Estado de conmoción interior ciñéndolo a un término inicial de noventa días prorrogable por dos periodos iguales; (iii) proscripción de juzgamiento de civiles por militares y no interferencia con las otras ramas del poder público; (iv) se elevó a rango constitucional el concepto de proporcionalidad de las medidas adoptadas frente a las causas de la perturbación, elemento que si bien ya había sido tratado por la jurisprudencia como conexidad en los Estados de sitio, adquirió una mayor trascendencia y limitó la discrecionalidad del Gobierno nacional; (v) se prohibió por el artículo 214 la suspensión de los derechos humanos y libertades fundamentales, así como el respeto de las normas del derecho internacional humanitario; y (vi) supresión del concepto previo del Consejo de Estado para la declaratoria, pero mantuvo los controles políticos en cabeza del legislativo y el juicio de exequibilidad por parte de la Corte Constitucional, además introdujo la reunión por derecho propio del Congreso y la potestad del Senado para no prorrogar la segunda vigencia del Estado de conmoción interior (García y Uprimny, 2009).

\section{El juicio de constitucionalidad sobre los decretos legislativos}

Como se dijo antes, a lo largo del tiempo la Corte Constitucional ha trazado una línea que demarca el alcance del control constitucional sobre los Estados de excepción, y de manera especial, ha establecido algunos presupuestos que deben considerarse para llevar a cabo el juicio de constitucionalidad sobre los decretos legislativos. En esa medida, para realizar el juicio sobre la constitucionalidad de los decretos legislativos, la Corte efectúa un examen integral de los mismos, es decir, en primer lugar, un control formal verificando el cumplimiento de los requisitos formales de los decretos legislativos, y luego un control material, sobre su contenido, atendiendo a distintos presupuestos, que se explicarán en las siguientes líneas:

\section{Examen formal}

Este examen se centra en contrastar los requisitos mencionados en la norma con los establecidos en la declaratoria. Así, basta con remitirse a lo preceptuado en el artículo 213 de la ley superior, donde se prescribe el contenido del decreto que declara el Estado de conmoción interior. Según este artículo la Carta condiciona la declaratoria de conmoción interior a cuatro presupuestos formales: (i) la expedición de un decreto que debe ser suscrito por el presidente de la República y todos los ministros; (ii) debe tratarse de un decreto motivado; (iii) debe indicarse si la declaratoria se hace en todo el territorio nacional o en una parte de él y (iv) la declaratoria del Estado de excepción debe ser por un término no superior a noventas días, prorrogable hasta por dos periodos iguales, el segundo de los cuales requiere concepto previo y favorable del Senado de la República (art. 213, CP).

Una vez que la Corte encuentra que los decretos declaratorios cumplen a cabalidad con los requisitos formales constitucionales y legales, podrá llevar a cabo el examen de los presupuestos materiales de la declaración del Estado de conmoción interior (sentencia 802/2002).

\section{Examen material}

La Corte hace una indagación más profunda frente a la concordancia de los presupuestos que señala la norma, como requisito para que se configure el Estado de excepción, y posteriormente realiza un juicio de suficiencia respecto al cumplimiento de los mismos. En resumidas cuentas, atendiendo a la jurisprudencia de la Corte Constitucional de Colombia, el examen material del control jurídico consta de varios elementos, que deberá tener en cuenta la misma corporación para determinar si el decreto legislativo vulnera o no el contenido de la Constitución, y son: el presupuesto fáctico, el presupuesto valorativo y el 
juicio de suficiencia sobre los medios ordinarios que tiene el Estado para conjurar la crisis.

Presupuesto fáctico: en el presupuesto fáctico la Corte hace una lectura de los hechos que fundamentan el Estado de conmoción interior -y que aparecen esbozados en la declaratoriay una ulterior verificación de su ocurrencia. El análisis se centra en el presupuesto "en caso de grave perturbación del orden público" que, según señala la Corte, parte de la ocurrencia de hechos concretos, perceptibles y, en consecuencia, verificables, que objetivamente generan una alteración de las condiciones de seguridad $y$ tranquilidad requeridas para el ejercicio de los derechos (sentencia C-802/2002).

Como suceso del mundo fenomenológico, el presupuesto fáctico, en sede de control constitucional, es susceptible de un juicio objetivo de existencia. Es decir, el juez constitucional debe determinar si la perturbación del orden público tuvo o no tuvo ocurrencia, pues por tratarse de un supuesto fáctico no hay alternativa distinta a la de haber o no haber ocurrido. En consecuencia, al presidente de la República no le es dado apoyar la declaratoria del Estado de excepción en un presupuesto fáctico inexistente.

Clara Elena Reales expresa que cuando la Corte estudia las características del análisis del presupuesto fáctico,

[...] le da mucho peso a los elementos probatorios para identificar los factores generadores de la crisis que dan lugar al Estado de excepción. Identificados los hechos, la Corte examina si se trata de hechos relevantes [...] de hechos determinantes [...] de hechos nuevos o sobrevinientes (2007, p. 652).

Presupuesto valorativo: en el presupuesto valorativo se hace un juicio sobre el presupuesto fáctico y en relación con la intensidad de la alteración y sus consecuencias, en este sentido la Carta dispone que "En caso de grave perturbación del orden público que atente de manera inminente contra la estabilidad institucional, la seguridad del Estado, la convivencia ciudadana [...]" (art. 213).

Como puede advertirse, este presupuesto ya no remite al supuesto de hecho en sí, esto es, a la perturbación del orden público como fenómeno directamente perceptible y verificable, sino que involucra un juicio de valor sobre ese supuesto fáctico. Se trata de una valoración relacionada con la intensidad de la perturbación y con sus consecuencias. Por un lado, no es cualquier perturbación del orden público la prevista en la norma superior sino una perturbación de naturaleza "grave". Además, el peligro debe ser "inminente", lo cual significa que debe haber un riesgo efectivo que puede materializarse en cualquier momento, se trata de un peligro potenciado por su inmediatez temporal (sentencia C-802/2002). Por otro, la alteración del orden público, "debe atentar de manera inminente contra la estabilidad institucional, la seguridad del Estado o la convivencia ciudadana" (art. 213). A criterio de Pedro Pablo Camargo (2008):

Estos conceptos son ambiguos e imprecisos, si se tiene en cuenta que Colombia desde su independencia ha estado en una permanente inestabilidad institucional. Por ende, la interpretación que de esta afectación le dé el ejecutivo puede ser bastante amplia dejando un considerable margen de discrecionalidad al presidente (p. 79).

El presidente tendrá que demostrar en la motivación del decreto legislativo que la grave alteración del orden público amenaza uno de esos tres ámbitos, para que la declaratoria del Estado de conmoción interior sea legítima. En consecuencia, el papel de la Corte en este presupuesto es verificar que la apreciación del ejecutivo no sea arbitraria o incurra en error manifiesto. Para Reales (2007) en general la Corte acepta la calificación que ha hecho el Gobierno, salvo que este haya alegado el hecho sobreviniente, o una consecuencia que no se deriva lógicamente de los hechos probados. 
Juicio de suficiencia: en este juicio se hace un análisis de la declaratoria de la conmoción interior, con relación al uso de los medios ordinarios de las autoridades de policía y la capacidad de estos para conjurar los hechos motivo de la perturbación. De este modo, la Corte debe constatar primero si existen medios ordinarios, si estos han sido usados, y si a pesar de existir, no resultan suficientes para superar la crisis (Reales, 2010).

Según este requisito, solo se puede acudir a la declaratoria del Estado de conmoción interior, cuando las herramientas jurídicas ordinarias con que cuenta el Estado, no permitan conjurar la grave alteración del orden público, que amenaza con disolver el acuerdo que posibilita la convivencia pacífica. En otras palabras, solo en el evento que, una vez verificados el presupuesto fáctico y el presupuesto valorativo, si en las atribuciones ordinarias de las autoridades de policía no existen mecanismos que ayuden a sortear la amenaza que se cierne contra el pueblo colombiano y la organización política por la que ha optado, es legítimo acudir a la declaratoria de conmoción interior.

Para Reales Gutiérrez (2007) "lo primero que debe constatar la Corte es si existen medios ordinarios, si estos han sido usados y si a pesar de existir no resultaban suficientes para superar la crisis" (p. 653).

Por lo tanto, el juicio de suficiencia le sugiere a la Corte la necesidad de emprender una evaluación mínima sobre la apreciación del primer mandatario respecto de la insuficiencia de las atribuciones ordinarias de policía; de verificar la anunciación de las medidas que en términos generales requiere el Gobierno para la superación de la crisis; de establecer si entre esas medidas y las causas de la perturbación del orden público existe una conexidad teleológica, finalmente, de constatar si se ha hecho una indicación general de las libertades que resulta necesario restringir (sentencia C-802/2002).

Además, es importante señalar que el análisis del juicio de suficiencia de las medidas ordinarias de policía debe ser global y no detallado, pues de lo contrario, se anularía el control que la Corte Constitucional debe emprender posteriormente sobre cada uno de los decretos legislativos de desarrollo?.

En consecuencia, el condicionamiento material que la Carta hace del Estado de conmoción interior no solo determina la legitimidad o ilegitimidad constitucional del decreto legislativo declaratorio, sino que, también constituye el ámbito de sujeción de los decretos legislativos de desarrollo dictados con base en él. De este modo, si el acto declaratorio no satisface ese condicionamiento, contraría la Carta y deberá ser retirado del ordenamiento. Si los decretos de desarrollo dictados con base en él no están directa y específicamente relacionados con los motivos de la declaración, contrarían también el texto superior y deberán ser declarados inexequibles (sentencia C-802/2002).

Solamente en ese marco constitucional, al presidente de la República le asiste la facultad de apreciar la suficiencia o insuficiencia de las atribuciones ordinarias de policía para conjurar la grave perturbación del orden público y sus implicaciones. No obstante, esa facultad no es absoluta ni arbitraria, pues en su ejercicio el mandatario debe sujetarse a los límites de los Estados de excepción fijados por la Constitución Política en su artículo 214, los tratados internacionales sobre derechos humanos y los tratados de derecho internacional humanitario ratificados por Colombia, sin olvidar los límites creados por la ley estatutaria sobre los Estados de excepción (ley 134/1994). Para terminar, debe tenerse en cuenta que los rasgos distintivos del control jurídico han sido definidos de manera expresa y clara por la Constitución en los artículos 214.6, 241.7 y 242 , y son:

\footnotetext{
Solo una vez se ha hecho el control automático de cada uno de los decretos legislativos de desarrollo, debe realizarse un análisis concreto y estricto sobre la insuficiencia de las atribuciones ordinarias de policía y sobre la consecuente necesidad de acudir a medidas excepcionales con miras a la conjuración de la crisis.
} 
1. El objeto de control son el decreto mediante el cual se declara el Estado de excepción, los decretos legislativos con los cuales se adoptan medidas para conjurar la situación extraordinaria y los decretos de prórroga de los Estados de excepción.

2. Es un control integral porque que se verifica que los decretos examinados reúnan los requisitos formales y materiales señalados por los preceptos constitucionales.

3. Es un control definitivo, pues una vez la Corte se pronuncia sobre la constitucionalidad de los decretos legislativos, estos no pueden ser objeto de un posterior examen vía acción pública de inconstitucionalidad.

4. Es un control participativo, ya que los ciudadanos podrán intervenir defendiendo o atacando la constitucionalidad de los decretos objeto de control.

5. El procurador general de la nación deberá rendir concepto.

\section{Otros controles: el control político y el control de legalidad de los decretos legislativos}

\section{El control político}

Según Nicolás Orejuela (2011) el control político es en un principio el control constitucional ejercido por órganos diferentes a los órganos judiciales ordinarios, cuyas características se pueden analizar desde diferentes facetas:

El control político tiene un carácter subjetivo, al no existir un precepto que regule la valoración, esta se soporta en la apreciación que realiza el órgano controlante; tiene un carácter de voluntariedad discrecional para ejercer o no el control y; finalmente, se rige por un criterio de oportunidad, puesto que el órgano que controla puede hacerlo por iniciativa propia sin que medie petición de otros órganos [...] (Orejuela, 2011, p. 38).
Debido a su naturaleza, si bien se trata de un control institucionalizado, esto es, de un control jurídicamente regulado, tiene un carácter subjetivo en cuanto a que su ejercicio está determinado en cada caso por la voluntad del Congreso, pues depende de esa voluntad la iniciación de una actuación de control, su trámite, su decisión y la imposición o no de una sanción al órgano controlado. No obstante, a diferencia del ya referido control jurídico, para Hernández Galindo (2001) este análisis se centra en

[...] la conveniencia, oportunidad, bondad, magnitud, aceptación, viabilidad, e interés público, sobre las medidas adoptadas por este, con el fin de contrarrestar la concentración del poder en el ejecutivo y los posibles abusos del mismo, es decir, ejercer una función democrática de contrapeso frente a las nuevas funciones que asume esta rama del poder público (p. 157).

Valga resaltar, la declaratoria de conmoción interior no interrumpe el funcionamiento del Congreso (art. 214, núm. 3 CP), el cual conserva la plenitud de sus atribuciones constitucionales y puede en cualquier época reformar o derogar los decretos legislativos ${ }^{8}$. Así, más allá de crear leyes, la principal función parlamentaria es la de establecer vigilancia y control sobre el poder ejecutivo (Vanegas, 1996), y es a la luz de esta concepción que el constituyente delega el control político al Congreso. Sobre este punto, la Corte Constitucional sostiene:

Como corresponde a un sistema constitucional democrático, en el cual estén contemplados instrumentos de control entre órganos para evitar la concentración de poder $y$ las posibilidades de abuso del gobernante, resulta apenas natural que el cuerpo repre-

\footnotetext{
8 Las sesiones especiales, según denominación de la doctrina, aceptada por la jurisprudencia, están previstas de manera específica para el ejercicio del control político por parte del Congreso, respecto de los decretos expedidos por el presidente de la República, en uso de las atribuciones extraordinarias que le confieren los artículos 212, 213 y 215 de la Constitución.
} 
sentativo de elección popular sea el que por derecho propio, y también como una función que justifica su existencia, fiscalice, desde las perspectivas de la conveniencia, la oportunidad, la viabilidad política y el interés público, la actividad del jefe del Estado cuando, por su propia determinación, asume un mayor cúmulo de facultades que pueden implicar restricciones a los derechos y libertades públicas y que de suyo -en los Estados de excepción-representan un desplazamiento de las atribuciones del Congreso hacia el Ejecutivo [...] (sentencia C-565/1996).

Pero, autores como Pedro Pablo Vanegas Gil (1996) ven limitados los poderes del legislativo al ejercer el control, puesto que ni en la Constitución ni en la ley se establecen métodos y tiempos para que este pueda tomar decisiones. El Congreso actúa como órgano político representativo de un Estado democrático y a él compete el seguimiento y cuestionamiento de las políticas del Gobierno de turno.

Por último, si bien es cierto que la sociedad que se representa en el Congreso como órgano político y deliberante, lo ve como una garantía, este control en Colombia es ineficaz. No se ha dado ningún debate al interior del foro democrático, sobre las medidas excepcionales adoptadas en los decretos legislativos por el presidente de la República y sus ministros durante el Estado de conmoción interior.

\section{El control de legalidad de los decretos reglamentarios proferidos durante la con- moción interior}

La ley estatutaria 137/1994 tiene por objeto regular las facultades atribuidas al Gobierno y el control de las mismas durante los Estados de excepción, es así como mediante aquella se establece un control adicional a los que ordena la Carta Constitucional, denominado control de legalidad. En efecto, en su artículo 20 esta ley determina que: "Las medidas de carácter general que sean dictadas en ejercicio de la función administrativa y como desarrollo de los decretos legislativos durante los Estados de excepción, tendrán un control inmediato de legalidad, ejercido por la autoridad de lo contenciosoadministrativo".

El control de legalidad se realiza sobre los decretos reglamentarios que dicta el presidente de la República como máxima autoridad administrativa, en ejercicio de las funciones que le otorga la Constitución Política, especialmente las contenidas en su artículo 189 numeral 11. Dichos decretos, que de ordinario reglamentan la ley, cumplen la misma función (reglamentar) en los Estados de anormalidad, solo que están direccionados a regular las medidas implementadas en los decretos legislativos declaratorios expedidos en desarrollo del Estado de conmoción interior. De igual forma sucede con el uso de la facultad reglamentaria en ejercicio de la función administrativa que tienen las entidades territoriales y demás organismos adscritos a la rama ejecutiva, siempre y cuando se trate de actos de carácter general y estén encaminados a reglamentar las medidas decretadas durante la conmoción interior.

Frente a este control, también denominado "control automático de legalidad", no existe mucha regulación, así lo ha reconocido en su jurisprudencia el Consejo de Estado, en la cual ha definido como características propias del control de legalidad, las siguientes:

En primer lugar, se trata de un proceso judicial, por lo tanto, la naturaleza del acto que lo resuelve es una sentencia, porque la competencia atribuida a la jurisdicción es la de decidir sobre la legalidad del mismo, lo cual corresponde hacer a través de aquella.

En segundo lugar, el control es automático, o como lo dice el art. 20 de la ley 137: "inmediato", porque tan pronto se expide la norma el Gobierno debe remitirlo a esta jurisdicción para ejercer el examen de legalidad correspondiente.

En tercer lugar, el control es integral en relación con los decretos legislativos respectivos y el art. 
$213 \mathrm{CP}$, pese a que la norma no lo señala en forma expresa, pero necesariamente debe ser así, pues si no opera por vía de acción -toda vez que es oficioso-resulta lógico que el juez asuma el control completo de la norma (véase Consejo de Estado, sentencia radicado 11001-03-15-0002010-00352-00(CA) del 1 de junio de 2010).

Por otra parte, el Consejo de Estado ha dicho que el control de legalidad es independiente del control constitucional ejercido por la Corte Constitucional, tanto en la oportunidad del pronunciamiento como en el sentido de la decisión que se profiera. Esta afirmación hay que analizarla en contraste con lo que ha dicho la Corte Constitucional en relación con la inconstitucionalidad por consecuencia, la cual consiste en que una vez es declarado inexequible el decreto madre, los demás decretos de desarrollo expedidos con base en el mismo, también deben desaparecer del ordenamiento jurídico. Sobre el control por consecuencia en la sentencia C-176/2009, la Corte Constitucional dijo:

[...] cuando es declarado inexequible el decreto declaratorio del Estado de excepción, deben desaparecer también del ordenamiento jurídico todas las normas que se expidieron en desarrollo de aquella, por ausencia de causa jurídica. Es decir, que el control de legalidad no resulta ser tan autónomo y puede llegar a ser un tanto dependiente del control jurídico, cuando previamente la Corte Constitucional se ha pronunciado en un determinado sentido y deja sin efectos jurídicos los decretos legislativos que tienen como base los decretos reglamentarios sujetos de control de legalidad por el Consejo de Estado. No obstante, luego la misma sentencia establece que "este tipo de inconstitucionalidad resulta solo cuando existe una relación de causa a efecto entre la norma causal o determinante y la derivada" (sentencia C-176/2009).

En conclusión, el control de legalidad, también llamado control automático de legalidad, pese a ser un control de carácter jurídico, no presenta incompatibilidad alguna con el control que ejerce la Corte Constitucional, ya que los mismos son realizados por corporaciones, con distintas jurisdicciones y sobre normas que difieren tanto en su contenido formal como material.

Otra cuestión importante y que ha impedido el control efectivo de las medidas adoptadas durante la declaratoria de los Estados de excepción por parte de la jurisdicción contencioso-administrativa, es que este control ha tenido poco desarrollo legislativo y jurisprudencial, lo que hace que aun en las más altas esferas de la referida jurisdicción, esto es, en el Consejo de Estado, no se tenga claridad sobre cuáles son las circunstancias en las que se debe ejercer dicho control. Lo anterior, de acuerdo con las aclaraciones y salvamentos de voto proferidos en varias sentencias de control realizadas por parte del máximo tribunal de la jurisdicción contencioso-administrativa.

\section{Conclusiones}

En Colombia el ejercicio de los poderes derivados del Estado de excepción por parte del ejecutivo ha sido una constante histórica de los Gobiernos de turno independientemente de su filiación política. No obstante, la vasta discrecionalidad de las decisiones del ejecutivo en el uso de sus atribuciones de emergencia, no ha sido suficiente para conjurar los graves problemas de orden público que afectan al país, convirtiendo el Estado de excepción en una figura ineficaz.

Por ello, uno de los objetivos principales del constituyente de 1991 fue limitar los poderes de la rama ejecutiva para los Estados de excepción, buscando fortalecer la labor de la rama legislativa, como órgano de representación democrática, porque con el incremento de las facultades extraordinarias en manos del ejecutivo se estaría privando al Congreso de la República de su más valiosa atribución: "hacer las leyes", en detrimento de los principios democrático, participativo y pluralista.

Tampoco puede perderse de vista, que el paso del tiempo hace pronosticar la existencia de 
mecanismos oportunos y más eficaces para dar respuesta dentro de la "anormalidad" a las situaciones de crisis, en las cuales no se puede abandonar el proceso de discusión pública de los conflictos en el foro natural de discusión, que por excelencia es el Congreso de la República. Por tanto, la procedencia de los Estados de excepción debe resultar cada vez más inusual, en virtud de que en la sociedad y en el ordenamiento jurídico colombiano existen instrumentos para enfrentar las crisis.

Sin duda alguna, la Constitución de 1991 y los organismos internacionales de protección de derechos humanos, prevén mecanismos y formas que les son propios, para responder de manera pronta e idónea a las crisis o alteraciones que ponen en peligro el orden público, social, económico o ambiental en Colombia. Por eso, durante los últimos años, las autoridades públicas han venido acogiendo paulatinamente la doctrina que prohíbe la utilización expansiva de los poderes excepcionales para resolver problemas crónicos o estructurales, sin que ello quiera decir en modo alguno que estos deban quedar huérfanos por parte del ejecutivo.

Para terminar, es necesario reiterar que el control ejercido por jueces y tribunales en el Estado constitucional contemporáneo resulta siendo la fórmula para la mejor relación seguridad jurídica-justicia, salvaguardando así el principio democrático. Pero, la democracia, más que grandes jueces, requiere grandes ciudadanos. La realización de las promesas sociales de muchas constituciones es un asunto demasiado serio para dejárselo únicamente a los jueces constitucionales.

\section{Referencias}

Barreto, A. (2006). Normalidad y excepcionalidad: la indescifrable regularidad contemporánea de la excepción. Disponible en: http://www.palermo.edu/derecho/ publicaciones/sela2006pdf/AntonioBarreto_Rozo.pdf
Camargo, P. (2008). Los Estados de excepción en Colombia ( $3^{\mathrm{a}}$ ed.). Bogotá: Leyer.

Consejo de Estado de Colombia. (2010). Sentencia radicado 11001-03-15-000-201000352-00. M. P.: María Claudia Rojas Lasso, 1 de junio.

Corte Constitucional de Colombia. (1992). Sentencia C-004. M. P.: Eduardo Cifuentes Muñoz, 7 de mayo.

Corte Constitucional de Colombia. (1996). Sentencia C-565. M. P.: José Gregorio Hernández Galindo, 6 de noviembre.

Corte Constitucional de Colombia. (2002). Sentencia C-802. M. P.: Jaime Córdoba Triviño, 2 de octubre.

De Sousa, B. \& García, M. (2001). El caleidoscopio de las justicias en Colombia. Bogotá: Siglo del hombre.

Gallón, G. (1987). La experiencia colombiana en Estados de emergencia y la viabilidad de su control internacional. En: D. GarcíaSayán (comp.). Estados de emergencia en la región andina (pp. 80-91). Lima: Comisión Andina de Juristas.

Gallón, G. (1979). Quince años de Estado de sitio en Colombia, 1958-1978. Bogotá: Librería y Editorial América Latina.

García, M. \& Uprimny, R. (2009). El control judicial de los Estados de excepción en Colombia. Dejusticia, Documentos de Discusión, pp. 1-28.

Gómez, P. (1985). Facultades extraordinarias y Estado de sitio. En: J. Cepeda (ed.). Estado de sitio y emergencia económica (pp. 147-176). Bogotá: Contraloría General de la República.

Hernández, J. (2001). Poder y Constitución (1 ${ }^{\mathrm{a}}$ ed.). Bogotá: Legis.

Iturralde, M. (2005). Estado de derecho vs. Estado de emergencia: los Estados de excepción y la construcción de la temporalidad del derecho en Colombia. En: D. Bonilla (eds.). 
Hacia un nuevo derecho constitucional (pp. 83-151). Bogotá: Universidad de los Andes.

Ley 137 de 1994. Por la cual se regulan los Estados de excepción en Colombia. Diario Oficial 41 379, 3 de junio.

Orejuela, N. (2011). Los Estados de excepción en Colombia. Cali: Universidad San Buenaventura.

Reales, C. (2007). El control de los decretos declaratorios de los Estados de excepción. En: J. Cepeda, E. Montealegre (dirs.) \& J. Alexei (coord.). Teoría constitucional y políticas públicas: bases críticas para una discusión (pp. 615-713). Bogotá: Universidad Externado de Colombia.
Uprimny, R. (2007). La judicialización de la política en Colombia: casos, potencialidades y riesgos. Sur. Revista Internacional de Direitos Humanos, 4(6), pp.52-69. Disponible en: http://dx.doi.org/10.1590/ S1806-64452007000100004.

Valencia, H. (1997). Cartas de batalla: una crítica al constitucionalismo colombiano ( $2^{\mathrm{a}}$ ed.) Bogotá: Fondo Editorial Cerec.

Vanegas, P. (1996). Los Estados de excepción en el régimen constitucional latinoamericano, una perspectiva comparada. Tesis de grado para optar por el título de abogado. Facultad de Derecho. Bogotá: Universidad Externado de Colombia. 